\title{
Chapter 1 \\ The Interplay of Digital Technologies and the Open Innovation Process: Benefits and Challenges
}

\author{
Pierre-Jean Barlatier, Anne-Laure Mention \\ and Avni Misra
}

\begin{abstract}
Innovating organizations are adopting and quickly implementing the open innovation (OI) approach for developing new products and services. There is a growing need to improve the process, to achieve faster and better outcomes. The integration of disruptive digital technologies (DTs) into the innovation processes bolsters the development of new business models, innovation processes, and ecosystems. However, there is limited information regarding the management of a digitalized OI process, and the role of different DTs across the stages of the innovation process. A conceptualized framework has been established, which integrates different DTs, and maps them across the stages of the OI process. The framework identifies the links between different dimensions and attributes of different DTs, such as big data, the IoT, cloud computing, artificial intelligence, blockchain and social media, and the stages of the OI process. The framework also provides a
\end{abstract}


consolidated approach for understanding the benefits and challenges of different DTs across the OI process.

Keywords. Open innovation, digital technologies, digitalized process, big data, IoT, cloud computing, artificial intelligence, blockchain, social media, integration, benefits, challenges, innovation outcome, implementation, business models.

\section{Introduction}

Innovation scholars and practitioners have suggested a range of solutions for innovation managers to use, to enhance the value delivered across innovation processes and their outcomes, which are steered in an OI setting (Chiaroni et al., 2011; Urbinati et al., 2018). An OI process is described as "the use of purposive inflows and outflows of knowledge to accelerate internal innovation, and expand markets for external use of innovation, respectively" (Chesbrough, 2003). Disruptive technologies support the development of radical business models, innovation processes, and ecosystems. Integration of digital technologies (DTs) in business processes has been the specific reason for major shifts in different industries. One of the key benefits of digitization has been to turn tangible objects into intangible ones, making them more portable and accessible (Rayna and Striukova, 2016). DTs have changed the face of innovation processes by triggering novel methods for stakeholder management, gaining competitive advantage, development processes, customer engagement, and data analysis (Brunswicker et al., 2015).

The importance of digitalized innovation processes has been appreciated by several organizations that have successfully applied a digital approach to manage their innovation activities (Chen et al., 2012). A digital innovation process can be described as a new way of developing new products and services, which are embodied in, enabled and managed by information technologies (Fichman et al., 2014). However, established research indicates that most organizations within different industries are feeble, and have a limited capability to benefit from a digitalized process (Parida et al., 2019; 
Porter and Heppelmann, 2015). Some of the key challenges currently faced by organizations in instigating a digital approach are related to identifying, selecting and implementing customized digital strategies aligned with the organizations' innovation activities (Sjödin et al., 2018). Another challenge is related to better understanding how to use a digital solution to develop, design, adapt, evaluate and market service-based offerings. Although previous contributions elaborated on understanding the value of digitalized OI processes within an organization, there still exists a need to deepen the understanding of the advantages and disadvantages associated with the implementation and organization of DTs across the stages of an OI process.

Thus, it is important to acknowledge the efforts that were made to compile, organize and share the knowledge on application of DTs in the innovation process as a part of the business model. Morabito (2016), in his book Future of Digital Business Innovation, discussed the main challenges of digital business innovation, and analyzed the increasing trends that would shape the future of business innovation. The chapters of the book covered insights from digital systems, digital management and the digital innovation perspective. Following a similar approach, Lazazzara et al. (2019) highlighted the links between individuals and their capability to handle the emerging new technology challenges, and their impact on digital innovation. The book was a compilation of papers that were grouped in four sections covering the impact of digital innovations on individuals, inclusion, and sustainability, for designing solutions for digital learning and organizing digital innovations. Another recent publication is a set of papers compiled by Aagaard et al. (2019), which focused on understanding the applications of digital business models across organizational processes, strategies and networks, to ensure successful management of digital business models within a value chain and their ecosystems. All three publications indicated the flexibility and fluidity offered by digitalized business approach, and its attempt to understand the impact on organizational decision-making. However, these works drew limited attention to the role and management of DTs specifically in the innovation process. Scholars have acknowledged (Agostini et al., 2017; Nambisan et al., 2017) that an 
interdisciplinary effort, involving scholars from different disciplines and addressing competitive issues in the area of digital innovation management, is essential for developing valuable theoretical and managerial advancements in the field.

Therefore, to address this growing need, the conceptualization and design of this book are structured to explore ways in which digital integration can be managed across an OI process. This book applies a macro- and micro-perspective to understand the role and management of DTs during the OI process. From a macroperspective, Chapters 2-9 establish a foundation for broadly linking DTs to the OI process. The combined chapters aim to understand the role and impact of DTs on the typologies of the OI process, the value-based outcome of the process, as well as outline the means by which innovation practices influence policies for innovation. Further, in the latter half of the book, Chapters 10-20 collectively adopt a micro-perspective to magnify and build upon the macroscopic foundations of the earlier chapters. Chapters 10-20 highlight the role of individual digital technology tools, their applications, associated complexities, and the role the DTs play in building organizational innovation capabilities. In alignment with Urbinati et al. (2018), DTs are tools that add value to the OI process by managing collaborations, sharing and creating knowledge, and transferring information across various activities, stakeholders and platforms. The heterogeneous and ambidextrous nature of the chapters included in this book suggest that the topic of a digitalized OI process is gaining attention, and has sweeping implications in the fields of innovation, information technology, economics and industrial marketing. In addition, this book discusses the challenges that the technologies are expected to impose during the process, so that organizations can customize the learnings to proactively design management strategies.

In doing so, a three-stage - define, design, and validate (Grönlund et al., 2010) - OI process has been adapted to observe the influence of DTs, such as big data (Chen et al., 2012; Sen et al., 2016), artificial intelligence (Lu et al., 2018), cloud computing (Ross and Blumenstein, 2015), the Internet of Things (Del Giudice and 
Della Peruta, 2016; Santoro et al., 2018), blockchain technology (Gausdal et al., 2018; Nakamoto, 2008), and social media. The purpose of developing an adapted integrated framework is to identify areas of influence where DTs offer value, benefits, and challenges across the stages (define, design, and validate) of the OI process. Using the lens of DTs to view the OI process is a rational approach, as it may assist in identifying useful strategic digital blueprints, to conduct and manage different inbound and outbound innovation activities at different stages of the process, to enhance the capabilities of the business models and value of the innovation process and its outcomes for the organizations. The chapters of this book intend to provide a profound understanding of the advantages of adopting DTs and extending their applications to different activities during OI.

This introductory chapter is structured as follows. The next section discusses an adapted integrated framework addressing the use and management of DT in the OI process in companies. This leads to the section that provides an overview of different DTs and their benefits as well as the challenges associated with different activities of the OI process in small- and medium-size enterprises (SMEs) and large organizations. The last section emphasizes the need to design a strategic digital approach for managing interactions between diverse stakeholders in an OI process.

\section{The Importance of Digital Technologies in Open Innovation Processes}

Radical technologies are providing a competitive edge to the innovation processes in a firm. The increased digitization of organizational processes and products poses new challenges for understanding product innovation. It also opens up new horizons for understanding the integration of DTs in OI processes. Digital transformation has undoubtedly become a key enabler of innovation as evidenced by numerous firms that use DTs to manage their innovation processes. The OI concept necessitates the integration of systems and technologies capable of converting the process into value. 


\subsection{The open innovation processes}

The activities during an OI process must be managed across different stages. Based on the model adapted from Grönlund et al. (2010), the three key stages of the OI process are "define, design, and validate." At the define stage of the process, the key activities are related to identifying strategic arenas of focus, consumer needs, areas of business opportunity, product ideas, concept evaluation, budget planning, and process planning. Following that, the design stage of the process focuses on development of the product, preliminary design, product testing, and planning production process. Last, the validate stage involves prototyping, planning launch, manufacturing reviews, market assessment, launch, devising measurement metrics, and a market review.

Chesbrough (2003) suggested firms can pursue an inbound OI process where firms internally use external knowledge. Alternatively, firms can pursue an outbound OI process where firms externally exploit internal knowledge, and design external pathways to the market. In the framework in Figure 1, all three stages of the process, define, design, and validate, can be pursued using the inbound or outbound OI approach, although Grönlund et al. (2010) emphasized that inbound and outbound activities should be simultaneously evaluated across all stages of the OI process. Digitalization of OI has been deemed an important approach for advancement (Agostini et al., 2017). Following on that approach partially, Urbinati et al. (2018) conducted an exploratory study, and examined the management of DTs across the stages of the OI process that pursued the inbound approach. The authors identified that there is a need for an approach that examines the role of DTs, using inbound and outbound OI perspectives. The need for understanding the implementation and management of DTs during OI has been emphasized in academia and in practice (Agostini et al., 2017; Bughin et al., 2008).

\subsection{Big data}

Iqbal et al. (2018) described big data as "huge volumes of high velocity, complex, and variable data that need sophisticated methods and 
technologies for data management and analytics." Firms that practice OI interact with many other organizations and individuals within their innovation network, to gather, assimilate, manage, accumulate, and analyze data from diverse sources, internal or external to the organization, with greater frequency. Large firms are focused on using big data as an innovation fuel to make real-time decisions for innovating and improving products and processes (Chen et al., 2012; Sen et al., 2016). AT\&T, one of the largest data providers in the United States, uses big data techniques to augment and build new customer experiences, to resolve or enhance a situation. In comparison to large corporations, SMEs have a flexible infrastructure, experience fewer governance barriers, and show more adaptability. Therefore, SMEs use big data to efficiently forecast demand, plan supply chains, and design data-driven operations analytics, create new businesses and develop focused innovation (Manyika et al., 2011; Sen et al., 2016). For example, Bism@rt, a European business intelligence company, used data generated from punching public transport tickets to develop a product to detect fraudulent activities in public transportation.

Big data integration in OI processes presents several benefits and challenges. It helps in creating transparency, by simply making data information more available across multiple platforms, and accessible to all involved stakeholders (Manyika et al., 2011). During the early stages of an OI process, access to big data helps in designing experiments to discover consumer needs, expose inconsistency and improve performance (Yang et al., 2017). In several industries, companies implement data-driven ideation strategies to develop new products, gain competitive advantage, and generate value from real-time information. The implementation of automated algorithms also assists in the process of market segmentation, during the stages of commercialization, which allows firms to design customized products and services to meet the needs of those segments.

However, unification of big data into OI processes has several limitations, such as processing and analyzing the data are time specific. Due to the high velocity, variety and volume of the data, storage is a key issue for small and large organizations 
(McKinsey Global Institute, 2013). The increasing variety of data demands new methods and technologies for managing the data (Kim et al., 2014). Another key issue is related to data security, which must comply with data encryption standards, methods, and algorithms (Nadeem and Javed, 2005; Yang et al., 2017). The unique link among smart devices and digital platforms contributes to gathering of the data; however, it poses privacy concerns for consumers who have the data digitally recorded (Cheatham, 2015; Michael and Miller, 2013; Yang et al., 2017).

\subsection{Artificial intelligence}

Artificial intelligence (AI) in the form of machine learning (ML) is developing rapidly (Lu et al., 2018). The application of AI is broad, encompassing algorithms to robotics, with wider applications in different industries (Lu et al., 2018). Firms are looking to gain competitive advantage through the implementation of AI in high-level processes. AI is managed to drive innovation by fast-tracking the process of new product development, which leads to elimination of redundant costs, and creates new ways of increasing profitability (Purdy and Daugherty, 2017). AI also assists firms in developing new products and services based on design goals and limitations. Several large organizations have incorporated AI technology into their innovation business processes. For example, Amazon uses transactional AI for predicting customer purchase behavior, and uses autonomous robots in delivery systems. Boxever, a company in the travel industry, relies heavily on machine learning to improve customers' experience, by engaging customers in their customer journeys (Adams, 2017). Industry reports by BCG (2015) in the consumer products sector showed that implementation of AI analytics on a large scale, in consumer-packaged goods (CPG) companies, can increase revenue by predictive demand forecasting, more relevant local products, custommade services, and enhanced experiences.

AI implementation demands new structures, of both centralized and decentralized activities, which is a challenging process. Using AI algorithms is limited to solving a specific type of problem at a given 
time. AI systems are complex. AI algorithms learn by consuming data, and training data is an integral part of the AI tool and the overall system. The complexity of the AI algorithm is manageable during small projects and isolated uses, but becomes increasingly tough to address as AI systems build on one another (BCG Focus, 2018). The application of AI requires skilled staff and investment in training of the staff. Despite these complexities, companies that invest heavily in DTs tend to advance more in AI, and reap superior value from its application.

\subsection{Cloud computing}

Foley (2008) described cloud computing as a technology that involves the use of highly scaled offsite IT resources, assembled in an Internet-based, computer-generated environment, expended based on the demand, and in the form of subscription business models, where multiple customers share capabilities. The rapidly changing market and consumer trends, due to the increasing demand of technology platforms (such as tablets, smart phones, apps, and webbased platforms) for mundane personal and professional activities, have pushed organizations to invest in cloud-computing integrated products and services (Ross and Blumenstein, 2015). For example, large organizations, such as IBM in collaboration with Sproxil, induce mobile and cloud computing technologies into their consumer data viewing and analysis process, to assist manufacturers in identifying and preventing drug imitation practices (Longwe, 2013). Accenture uses an OI model to develop new technologies, where it incorporates knowledge from internal and external stakeholders, during workshops that are run using cloud-computing platforms (system, application, and products for data processing (SAP) technology) and virtualization techniques (Isse, 2010).

Cloud computing is greatly beneficial for SMEs, as it moderates disadvantages related to capacity building and financial planning (Misra and Mondal, 2010; Ross and Blumenstein, 2015). Another extended application of cloud computing for SMEs is access to a global ecosystem, as this technology allows quick and easy 
deployment of applications across all connected cloud networks, which provides more transparency in the process, and increases accessibility to external knowledge and resources, ultimately enhancing the outcome of the OI within small firms (Conway and Curry, 2012; Prashantham, 2013). Cloud-based technologies support international collaborations for SMEs, by linking them to form potential partnerships with different investors, and pitch their entrepreneurial ideas using crowdfunding platforms, such as Kickstarter or CLOUDCube (Nisen, 2012). Cloud services are being widely adopted by industries ranging from healthcare and banking to retail.

Cloud computing plays an important role in OI processes, as they reduce the up-front infrastructural costs, and increase price flexibility as firms adopt pay-on-demand business models, reducing the requirement for space and other utilities. Companies now invest in operation costs more than capital expenses. Cloud computing also enhances business agility, as it accelerates the time to market for products, as firms incorporate competitive information technology strategies. Cloud computing further facilitates the design stages of an OI process as it provides an opportunity for testing new software, evaluating third-party applications, meeting the demand for increasing resources, and efficiently dealing with technology issues (Neves et al., 2011).

Cloud computing technologies are not implemented without dealing with their operational challenges, particularly related to organizational readiness (Ross and Blumenstein, 2015). The key issues with the implementation and use of cloud computing technology are related to data security and privacy. This technology also requires dealing with compliance issues and legalities which may extend the timelines of the innovation process, and further delay commercialization. Cloud computing also requires extensive training, and a large initial investment (starting cost) to shift from conventional computing platforms to contemporary state-of-the-art facilities, a daunting issue for small firms, and a complex process for large organizations. The lack of a standard open architecture is another prominent issue with cloud-based services. It adds flexibility to the process but also raises conflicts due to continuous integration 
of new stakeholders and cloud providers (Conway and Curry, 2012; Dillon et al., 2010). Nonetheless, cloud-based services are becoming an important innovation driver for achieving competitiveness and efficiency within organizations across their innovation timelines. Due to the widespread accessibility of cloud computing, the lack of such a technology would make it difficult for an organization to adapt to customers' changing needs.

\subsection{Internet of things}

Modern firms are progressively developing and employing disruptive information and communication technology systems (ICTs) in numerous business processes to boost the level of innovativeness through contemporary methods of knowledge streaming and information gathering (Santoro et al., 2018; Solima et al., 2016). The IoT is a DT designed to connect the virtual world through the Internet to everyday technology objects in the real world (Rosyihan and Samira, 2017; Samani et al., 2015). The application of the Internet of Things (IoT) can create a far-reaching network of smart devices that are automated, capable of sharing knowledge, transferring data, and responding to external environmental stimuli (Madakam et al., 2015). The manifestation of IoT technology facilitates the management and distribution of knowledge at reduced cost that can extend, and overcome, the boundaries of innovating firms and research organizations, and thus, support the OI effort (Rosyihan and Samira, 2017). IoT technology is largely applied across diverse industries, specifically during the product development stages as they provide smart and flexible manufacturing processes (Manyika et al., 2015). In an open and shared IoT-driven environment, firms can integrate technologies of internal databases with external databases, to deliver collaborative and diverse innovation outputs.

Samsung, competitively one of the largest telecommunication players in the market, leveraged IoT technology by developing a prototype (beta version) IoT platform, ARTIK, to connect developers across the globe to develop and test applications for the platform (Narsalay et al., 2017). The contribution of the IoT in the validate 
phase of the OI process involves practices related to customer engagement, product delivery, end-user monitoring, and post-launch tracking. For example, Haier, the world's fastest growing home appliance company, manages its production processes for manufacturing washing machines in China through an IoT-integrated mass customization platform called COSMOPlat, which integrates customer orders, suppliers in accessing components and manufacturers within an automated process to deliver customized products to customers (Haier, 2018). In small organizations, the IoT improves customer interaction, improves efficiency, identifies market trends, and reduces operational cost. Aqua Running, a successful innovative company, has developed sensor-based IoT technology-integrated body suits for no-impact training in water. This use of the IoT has led to exponential growth for the company.

Some key challenges that stem from IoT implementation during the process of OI require deeper collaboration strategies than traditional innovation methods (Leminen et al., 2015). Other issues include complexity that arises due to interoperability, as a result of using heterogenous systems across multiple stakeholders that can decelerate the OI process, issues related to data security management, due to the extended reach and wide networks; management of the data analytics process, due to the requirement of proficient and technically skilled human resources; and the trustworthiness of the outcomes, due to the reliance on machine-based judgment of unstructured data and human interpretation of the data (Daecher et al., 2018).

\subsection{Blockchains}

Blockchain technology is defined as "a shared, distributed ledger that facilitates the process of recording transactions and tracking assets in a business network" (Gupta, 2017). Blockchain technology has wide applications in the OI process due to its characteristics of immutability, decentralization, and timestamped record keeping, which facilitates by reducing the issues that arise due to multiple stakeholder involvement and it accelerates the process of innovation 
adoption (Nakamoto, 2008; Gausdal et al., 2018). Large organizations, although only a few, are integrating blockchain technology in their business processes. For example, IBM uses blockchain applications as a tool to simplify interorganizational transactions and collaborations (Gupta, 2017). The shipping industry is expansively using blockchain technology in its supply chains. For example, Maersk, a shipping company in a joint venture with IBM, is developing a blockchain-based open industry platform to connect the multiple channels of its supply chain and provide benefits to different parts of the ecosystem. Tradeshift, a medium-level organization, implements blockchain back-end technology called Tradeshift Pay to offer early invoice payments to its suppliers.

The automated approach of the blockchain technology attracts the interest of several industries (De La Rosa and Gibovic, 2019). The management of OI processes is a complex task, as collective intelligence and coordination are not easy to collate, due to lack of a controlled and efficient system for recognizing the needs and contributions of individual stakeholders (Duvaut et al., 2018; De Le Rosa and Gibovic, 2019). The integration of blockchain technology works as an efficient management tool for systematizing operations, resources, information, and simplifying communication among stakeholders (Gausdal et al., 2018). A controlled and transparent blockchain system increases trust among stakeholders and provides direct interactions between multiple actors of the network without investing in a trusted intermediary. In addition, automated contractual arrangements, accelerate the OI process by providing timeefficient and cost-effective capabilities (De Le Rosa and Gibovic, 2019). Blockchain applications can also fast-track OI processes by increasing the efficiency of the regulatory approval processes, as the technology can enable regulatory bodies to issue electronic approvals using a secure code that cannot be duplicated.

Integration of blockchain technology into the OI process establishes a completely new information-sharing dynamic across the innovation ecosystem. However, such an assimilation of technology is accompanied by a plethora of challenges. Organizations that are implementing blockchain into their OI process need to be proactive 
in their approach. Contingency planning is required to prepare for any limitation that is raised due to lack of organizational readiness in this context. One of the key challenges with blockchains relates to the wealth of initiatives to establish a regulatory framework for blockchain applications, most of which still are a work-in-progress. Issues related to storage capacity, scalability, security and data privacy have been highlighted as common problems associated with blockchain technology across different industries (Reyna et al., 2018). It is difficult to create a blockchain network by linking one blockchain to another, and also the level of compatibility between the new blockchain systems with existing transaction platforms in an organization is weak (Yamada et al., 2017).

\subsection{Social media}

Social media is a set of digital tools open for public involvement that acts as a platform for developing, collecting, and sharing knowledge capable of building relationships through interaction and collaboration (Kim and Ko, 2012). In the process of OI, social media acts as a tool for research and development, and communication during early and later stages of the process (Mount and Martinez, 2014). Social media also acts as a sourcing tool, where in organizations in an outside-in process, social media can assist in integrating external actors into the process (Rekece et al., 2012). Social media platforms, such as online communities, social networks and blogs, and opensource platforms allow a data-driven organization to study consumer behavior, and understand the needs of their market, to ideate new products and test concepts in the market (Grabs et al., 2015). Social media is used for activities related to collaborations, information exchange and crowdsourcing during the ideation stages of the process (Mount and Martinez, 2014; Rekece et al., 2012).

For example, Cisco conducts an iPrize initiative each year, and invites external contributors worldwide to submit business concept ideas online, which are further developed by Cisco. In the same vein, Lego uses a customer-driven innovation approach, in which the company engages customers through the Lego website to design new 
Lego products and vote on other designs, providing suggestions for improvement. The winning idea gets a $1 \%$ stake in the project if it takes off. By dedicating this space to consumers, Lego integrates them in the company's ideation and R\&D processes (Lafley and Charan, 2014). Comparatively, for SMEs, the use of social media and networks facilitates collaborations in the OI process at a much larger scale, as SMEs deal with problems related to limited financial resources, a lack of specialized experts and inadequate internal capabilities to innovate.

Social media platforms provide speed, flexibility, extended reach, and interactivity, which helps in gathering external information for product development, management tools, and platforms for interactions (Parveen et al., 2015). Social media also drives internal co-creativity within an organization which keeps the internal stakeholders informed and involved in the process (Sigala and Chalkti, 2015). Mention et al. (2019) discussed different ways in which social media assists in decision-making at different stages of the innovation process, by influencing firms' strategic actions, and at different levels of stakeholder engagement. During activities related to research and development, the implementation of social media tools reduces market research costs, by providing market insights and access to a loyal consumer base, as they are engaged with the organization's social media pages on different platforms. Continuous observations of social media networks and online communities promote OI at the validate (commercialization and testing) stage, as companies collect opinions about not only their own products and services but also competitive offerings in the market. Social media also assists in designing communication campaigns for marketing the product (Fensel et al., 2012; Kasper and Kett, 2011; Loukis et al., 2017; Zhang and Vos, 2014).

Although the implementation of social media in OI activities promotes the process, it is accompanied by several challenges. One of the key challenges is related to the speed and scale at which organizations must manage the data obtained from social media sources. In addition, issues related to crowdsourcing activities (such as the quality, adequacy diversity, and efficacy of the collected data) have 
been identified, which could be presented with a possible bias and manipulations, thus leading to the development of improper insights (Agafonovas and Alonderiene, 2013; Bott and Young, 2012; Loukis et al., 2017). In terms of social platforms and technology, limitations associated with centralized control and regulations are a common challenge across all stages of the process. Exploiting social tools for the OI process provides a more customized approach to engage stakeholders in the process. However, due to the large amount of data and the fast-paced environment, and constantly new emerging platforms, such processes are increasingly complex to manage.

Therefore, we emphasize recent contributions related to the use and application of DTs, such as big data, AI, cloud computing, the IoT, blockchains, and social media, highlighting their attributes to nurture activities relevant to OI. Each technology plays a key role in different phases - outbound and inbound, and different stages (define, design, and validate) — of the OI process. For the development of such complex DTs, experts rely on the orchestration of reliable resources and capabilities, and their effects are measured using pre-designed algorithms. However, the technologies are not always favorable for all activities of the innovation process and are accompanied by disadvantages for each technology. The next section discusses the definition, role, and impact of different DTs during the OI process.

\section{Toward a Digitalized Open Innovation Framework}

The distinctive characteristics of DTs add complexity to innovation processes, as they are fast-paced and difficult to control and depict high levels of uncertainty of outcomes (Nylén and Holmström, 2015; Yoo et al., 2012). Therefore, firms need a deeper understanding of the contribution, opportunities and challenges that are associated with the integration of DTs, to support the management of their digitalized innovation processes. To this end, the proposed framework in Figure 1 attempts to establish the links between the stages of an OI process and the different DTs. This aids in identifying the 
areas of influence during the three stages, define, design, and validate (Grönlund et al., 2010), of an OI process, where DTs such as big data, AI, cloud computing, the IoT, blockchain, and social media, have impacted the management of the ideation, conceptualization, development, and commercialization activities of the process.

The reason for keeping the concepts broad in the framework is to allow interdisciplinary investigations in alignment with the adaptable and flexible nature of DTs and the OI process (Yoo et al., 2012; Chesbrough, 2003). Viewing the OI process using a DT perspective is based on the following considerations: (1) Digital innovation has been considered an essential element of the business model for an organization, as it creates, delivers, and seizes business value for different stakeholders (Fichman et al., 2014). (2) Digitalization as an open resource reduces costs, increases transparency, expands distribution and access to control and resources, and enables streamlined collaborations (Brunswicker et al., 2015). (3) In combination with an OI process, DTs increase knowledge and resource heterogeneity, and efficiently manage a multi-channel, multi-stakeholder, and multi-stage process (Nylén and Holmstrom, 2015).

A digitalized OI process provides an unprecedented opportunity for managers and business leaders to flourish and contribute to the growing economy of digitalized products and services. To manage the complexity of digitalized processes, organizations must understand the overall capacity of the technology to deliver a diverse and large data-driven output offhand. Without a clear understanding of the ambiguities that are associated with the implementation of DTs, firms might not be able to employ the right strategic approach to exploit the paybacks and opportunities presented by these technologies. It is pertinent for organizations to develop prior knowledge regarding the type of factors that stimulate the adoption of DTs, the return on investment of digitally developed innovations, the availability of multiple options for DTs and updated knowledge of new DTs that is relevant to the business model.

The proposed framework in Figure 1 provides a point of reference for innovative organizations toward an integrated digitalized OI strategy. To assist organizations in making these decisions, the 


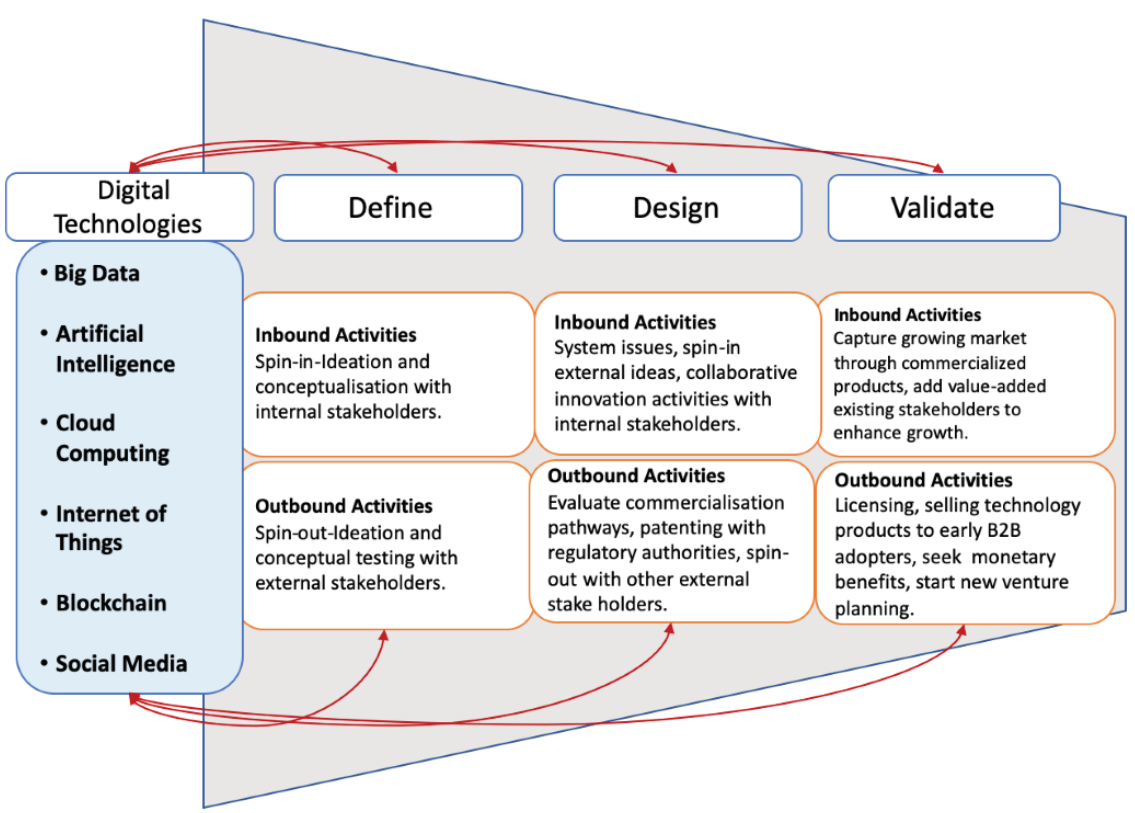

Figure 1: Integrated framework showing the influence of DTs on the stages of the OI process.

proposed integrated framework can provide a well-defined understanding of the different activities within an OI process linked to the characteristics of different DTs that can help in managing the process. The following section unfolds the discussions around the OI process, its different phases and stages. The framework conceives the role of different DTs across the stages of the OI process. The framework also establishes the impact of the different dimensions of each digital technology, and the benefits and challenges the technologies add to the management of different activities of the OI process at each stage. Therefore, the framework represents the key area of focus where the attributes and dimensions of each DT are mapped across the stages of the OI process. It further assists in identifying the managerial decisions that organizations must make at the process level to successfully implement the DTs in an OI (Chiaroni et al., 2011; Urbinati et al., 2018). 


\section{Extensions of Digital Technologies in the Management of Open Innovation}

The need for examining the role of DTs in OI is increasingly receiving attention in scientific research and in practice. This book aims to contribute to the growing body of literature by suggesting strategies for integrating DTs into the operations and activities of the OI process. This introductory chapter of the book discusses the strategic macro- and micro-perspectives of the book. At the macro-level, the book provides a logical flow of information by setting the foundations for the framework. Using a macro-approach, the authors view the overall OI process and the integration of DTs in the process, from a management, value creation and policy perspective. This sets a foundation for further examining the management of DT integration in the OI process using a micro-approach, by outlining the areas where DTs play an important role and discussing the implications of this mix. The micro-approach taken in the latter half of the book discusses the role and application of individual DTs in the OI process. It is useful to apply a micro-lens later, as it bridges the links between the different mechanisms of the DTs, and the activities and stages of the OI process.

Wåge and Crawford in Chapter 2, "Innovation in Digital Business Models," and Müller, Traub, Gantner and Voigtin in Chapter 3, "Managing Digital Disruption of Business Models in Industry 4.0," discuss a macro-approach for uncovering the broad applications and management of different DTs, and highlight the key characteristics of the technologies, and related knowledge, which help in framing digital strategies for improving organization's OI process and development of digital business models, leading to valuable innovation outcomes. The discussion about digitally transformed business models for innovation is further extended by BurgerHelmchen and Siegel in Chapter 4, where the authors make a highly novel contribution by expanding an understanding of the management of crowdsourcing platforms and their integration into innovation business models, and the challenges associated with this approach. The process of crowdsourcing has its own challenges that 
hinder the participation of the crowd at the later stages of the innovation process. Lykourentzou, Thomos, and Szlávik dedicate Chapter 5 to the exploration of the challenges that hinder the process, and ways in which crowdsourcing can be managed efficiently during the OI process. In doing so, they propose a well-researched framework that is based on modular workflows to manage efficiency.

An important dimension of a business model is the cost-benefit analysis. It is important for organizations to develop appropriability mechanisms, such as patents, copyrights, trade secrets, and different marketing efforts, to retain profits from the innovations. The existing appropriability mechanisms are well suited for traditional innovation processes; however, the need for a nuanced appropriability mechanism, and the ways in which it can be designed, are discussed by Long in Chapter 6, as the author identifies new challenges in exploring appropriability in the era of digitalized innovations, and the ways in which firms can address those challenges.

In the similar macro-sphere, Chapter 7, authored by Pikkarainen, Gomes, Ranta, Ylén, Iivari, and Hurmelinna-Laukkanen, focuses on understanding the management of innovation processes using a network orchestration and system dynamics approach, to create and capture value to design a data-driven support system for policy makers. To further explain the impact of innovative technologies on innovation policies, Prem in Chapter 8 elaborates on the integration of DT into the OI process, using a policy perspective, highlighting how changing innovation trends significantly impact innovation practices.

The micro-perspective is adopted from Chapter 9 onward, where authors adopt multiple lenses to examine the application of different DTs in the OI process. To explore the role of big data, in Chapter 9, Rantala, Palomäki, and Valkokari study the challenges faced by business-to-business (B2B) companies during the process of innovation, due to the application of big data, guiding researchers to underscore the importance of understanding the data utilization level and needs from the company and customer perspectives, and to understand the importance of creating a new business by applying a data business strategy. Chapter 10 (Koldewey, Reinhold, and 
Dumitrescu) and Chapter 11 (Bertin and Schaeffer) focus on improving the process of external and internal integration during the OI process, as the former presents an analysis of a business model environment, elucidates how value is created by designing and implementing smart services for external stakeholder integration, and suggests ways to create value. The latter chapter emphasizes the development of innovative capabilities for improved and balanced management of internal rigidities and external constraints during the era of digital OI.

One of the key challenges with the management of a digitalized OI process is managing the process of sourcing and applying external knowledge, and developing the capabilities of an organization to absorb knowledge from external sources. A combination of chapters in this book suggests ways for managing the process and the impact of crowdsourcing. In Chapter 12, Ruiz, Brion, and Parmentier explore the process of crowd knowledge absorption when firms implement crowdsourcing for innovation. Using this approach, the authors highlight the difficulties that firms face in developing absorptive capacities, and the weakness of the integrative actions taken by firms to manage the process. To improve the absorption capabilities for knowledge absorption, and to manage activities, such as knowledge sharing and development, innovating organizations need to adopt multiple data-driven digital enablers, such as cloud computing, AI, and the IoT in their business models. In Chapter 13, Hilbig, Hecht, and Etsiwah suggest the application of different types of data-driven business models, and identify the differences between pure data-driven business models, data-enhanced business models, and low-data business models, and how each approach creates and delivers value to the customer. Along the same lines, the key competences that are important for the development of digital products and services are examined by Kinkel, Rahn, and Rieder in Chapter 14. The study suggests competence needs, such as agile and designoriented development methods in-house, are important for companies, to develop digitalized outcomes. Another key requirement for managing digitalized innovation is the readiness of companies to accelerate the experimentation, testing, and learning process. 
External and internal stakeholder collaborations are sources of knowledge for the OI process, sometimes also referred to as intermediaries. The management of OI intermediaries specifically during the crowdsourcing process is a complex task, due to the diverse nature of the sources. A digitalized solution for tracking the interactions between diverse intermediaries involves the use of blockchain technology. In Chapter 15, Schenk, Schaeffer, and Pénin examine the impact of blockchain technology on OI intermediaries in a crowdsourcing innovation setting. The study identifies that although blockchain technologies are impactful for enhanced management of the OI process, not all firms have the capability to implement the technology in house. Therefore, open intermediaries can contribute in the implementation of blockchain technology and manage the impact on OI. Continuing the discussion about information management from diverse platforms, Patrickson and Johnson in Chapter 16 emphasize the integration of blockchain technology through automated blockchain ecosystems. Drawing on the concepts of co-operative gamification and design principles, Patrickson and Johnson suggest eight key principles that, if followed, can lead to the development of creative blockchain ecosystems. Such automated ecosystems, although limiting control over transactions, provide access to powerful information resources through a social exchange system, which further facilitates the OI process.

Extending the discussion further, Singh in Chapter 17 broadly discusses the role of social media in OI strategies, by suggesting the potential applications of social media in organizational innovations for managers and businesses and provides an account of best practice approaches that have led to organizations' successful leveraging of social media. In the same vein, in Chapter 18, Beckh, Beck, and Badillo shed additional light on the contribution of social media as a source during the OI process, focusing on SMEs. In doing so, they suggest a framework that studies the impact of different characteristics, attributes and factors of social media on the OI process. The book wraps up with Bénédic discussing the role of social media platforms (LinkedIn) in the process of new service development in Chapter 19, highlighting the benefits that practitioners can obtain by integrating the platforms into mundane innovation activities, such as networking, data analysis, and idea generation. Table 1 summarizes the contributions of this volume. 
Table 1: Benefits and challenges of DTs across the OI process.

\begin{tabular}{|c|c|c|c|c|}
\hline $\begin{array}{l}\text { Digital } \\
\text { technology }\end{array}$ & $\begin{array}{l}\text { Stages } \\
\text { of OI }\end{array}$ & Benefits & Challenges & Contributions \\
\hline \multirow[t]{3}{*}{ Big data } & Define & $\begin{array}{l}\text { Increases data availability and } \\
\text { transparency across multiple } \\
\text { platforms. Helps in designing } \\
\text { experiments to discover consumer } \\
\text { needs, expose inconsistencies and } \\
\text { improve performance. }\end{array}$ & $\begin{array}{l}\text { The processing and analysis of the data } \\
\text { are time specific. } \\
\text { The high velocity, variety, and volume of } \\
\text { the data storage are key issues. }\end{array}$ & \multirow[t]{3}{*}{$\begin{array}{l}\text { "Challenges of Creating } \\
\text { New B2B Business } \\
\text { through Big Data } \\
\text { Utilization" } \\
\text {-T. Rantala, } \\
\text { K. Palomäki } \\
\text { K.Valkokari }\end{array}$} \\
\hline & Design & $\begin{array}{l}\text { To develop new products, gain } \\
\text { competitive advantage and generate } \\
\text { value from real-time information. }\end{array}$ & $\begin{array}{l}\text { The increasing variety of data demands } \\
\text { new methods and technologies for } \\
\text { data management. }\end{array}$ & \\
\hline & Validate & $\begin{array}{l}\text { Allows firms to design customized and } \\
\text { tailored products and services to meet } \\
\text { the needs of those segments. }\end{array}$ & $\begin{array}{l}\text { Key issue is related to data security } \\
\text { which needs to comply with data } \\
\text { encryption standards, methods and } \\
\text { algorithms, and poses privacy } \\
\text { concerns for consumers. }\end{array}$ & \\
\hline \multirow[t]{2}{*}{$\begin{array}{l}\text { Artificial } \\
\quad \text { intelligence }\end{array}$} & Define & $\begin{array}{l}\text { AI for predicting customer purchase } \\
\text { behavior. }\end{array}$ & $\begin{array}{l}\text { Demands new structures, of centralized } \\
\text { and decentralized activities. Also } \\
\text { affects staffing issues in terms of skill } \\
\text { shortages. }\end{array}$ & $\begin{array}{l}\text { "Planning a Smart } \\
\text { Service Business } \\
\text { Integrating External } \\
\text { Partners" } \\
\text { — C. Koldewey } \\
\text { J. Reinhold } \\
\text { R. Dumitrescu }\end{array}$ \\
\hline & Design & $\begin{array}{l}\text { Allows predictive demand forecasting, } \\
\text { fast-tracks the }\end{array}$ & $\begin{array}{l}\text { AI algorithms become difficult to address } \\
\text { multiple systems build on }\end{array}$ & $\begin{array}{l}\text { "Organizational Impact } \\
\text { of Digital Open } \\
\text { Innovation in Retail } \\
\text { Banks: }\end{array}$ \\
\hline
\end{tabular}


Table 1: (Continued)

\begin{tabular}{|c|c|c|c|c|}
\hline $\begin{array}{l}\text { Digital } \\
\text { technology }\end{array}$ & $\begin{array}{l}\text { Stages } \\
\text { of OI }\end{array}$ & Benefits & Challenges & Contributions \\
\hline & & $\begin{array}{l}\text { innovation process, eliminates } \\
\text { redundant costs and increases } \\
\text { profitability. }\end{array}$ & $\begin{array}{l}\text { one another. AI can solve one problem } \\
\text { at a time. }\end{array}$ & $\begin{array}{l}\text { Managing External } \\
\text { and Internal Pressure" } \\
\text { - C. Bertin } \\
\text { V. Schaeffer }\end{array}$ \\
\hline & & $\begin{array}{l}\text { Creates virtual prototype iterations, and } \\
\text { compares their function, cost and } \\
\text { material. }\end{array}$ & & \\
\hline & Validate & $\begin{array}{l}\text { ML to improve the customer experience } \\
\text { by engaging customers in their } \\
\text { customer journeys, local product } \\
\text { development, customization, enhanced } \\
\text { marketing and sales promotion ROI. }\end{array}$ & $\begin{array}{l}\text { Requires skilled staff, investment in } \\
\text { training and the size of the } \\
\text { organization. }\end{array}$ & \\
\hline \multirow{3}{*}{$\begin{array}{l}\text { Cloud } \\
\text { computing }\end{array}$} & Define & Enhances business agility. & Data security and privacy. & \\
\hline & & & $\begin{array}{l}\text { Extensive training and large initial } \\
\text { investment. }\end{array}$ & \\
\hline & Design & Access to a global ecosystem. & $\begin{array}{l}\text { Operational challenges, particularly } \\
\text { related to organizational readiness, } \\
\text { raises conflicts due to continuous } \\
\text { integration of new stakeholders. }\end{array}$ & $\begin{array}{l}\text { "From Knowledge } \\
\text { Capture to Knowledge } \\
\text { Integration, the Key } \\
\text { Role of Integrative } \\
\text { Actions in } \\
\text { Crowdsourcing for } \\
\text { Innovation" }\end{array}$ \\
\hline
\end{tabular}


Easy deployment of applications across all connected cloud networks.

Reduces the up-front infrastructural costs.

Validate Increases accessibility to external knowledge.

Supports international collaborations.

Accelerates the time to market.

$\begin{array}{ccc}\begin{array}{c}\text { Internet of } \\ \text { Things } \\ \text { (IoT) }\end{array} & \text { Define } & \begin{array}{c}\text { Can integrate technologies of internal } \\ \text { databases with external databases. }\end{array} \\ & \text { Design } \quad \begin{array}{c}\text { Capable of sharing knowledge, } \\ \text { transferring data, and responding to } \\ \text { external environmental stimuli. }\end{array}\end{array}$

Provide smart and flexible manufacturing processes.

Validate Facilitates the management and distribution of knowledge at reduced cost.
- E. Ruiz

S. Brion

G. Parmentier

Legalities which may extend the timelines and delay commercialization.

"Berlin Start-ups - The Rise of Data-Driven Business Models"

- R. Hilbig

S. Hecht

B. Etsiwah

Data security management due to the extended reach.

OI requires deeper collaboration strategies than traditional innovation.

"Competences for the In-House Development of Digital Innovations in German Mechanical Engineering Companies"

Management of the data analytics.

- S. Kinkel

J. Rahn

B. Rieder 


\begin{tabular}{lllll}
\hline $\begin{array}{l}\text { Digital } \\
\text { technology }\end{array}$ & $\begin{array}{c}\text { Stages } \\
\text { of OI }\end{array}$ & Benefits & Challenges & Contributions \\
\hline
\end{tabular}

systems across multiple stakeholders.

Delivers collaborative and diverse innovation outputs.

\section{Blockchain Define Simplifies communication among stakeholders.}

\section{Provides direct interactions between} multiple actors.

Design Simplifies inter-organizational transactions and collaborations.

Works as an efficient management tool for systematizing operations.

Validate Accelerates the process of innovation adoption.

Provides time-efficient and cost-effective capabilities.

Increases the efficiency of the regulatory approval processes.
Trustworthiness of the outcomes, due to the reliance on machine-based judgment.

OI process needs to be proactive.

Storage capacity, scalability, security, and data privacy.

Lack of organizational readiness.

Regulatory framework for blockchain applications is limited.

"Blockchains and the Future of Open Innovation Intermediaries"

- E. Schenk

V. Schaeffer

J. Pénin

"Playful Design for Creative Blockchain

Ecosystems"

- B. Patrickson M.P. Johnson

Difficult to create a blockchain network by linking one blockchain to another.

The level of compatibility between the new blockchain systems. 


\begin{tabular}{|c|c|c|c|c|}
\hline \multirow[t]{7}{*}{ Social media } & \multirow[t]{2}{*}{ Define } & $\begin{array}{l}\text { Acts as a sourcing tool. } \\
\text { Allow a data-driven organization to } \\
\text { study consumers' behavior. }\end{array}$ & \multirow[t]{3}{*}{$\begin{array}{l}\text { Key challenges are related to speed and } \\
\text { scale. }\end{array}$} & $\begin{array}{l}\text { "What Is the Role of } \\
\text { Social Media in Open } \\
\text { Innovation } \\
\text { Strategies?" } \\
\text { — S.K.G. Singh }\end{array}$ \\
\hline & & $\begin{array}{l}\text { Ideate new products, and test concepts in } \\
\text { the market. }\end{array}$ & & \\
\hline & \multirow[t]{2}{*}{ Design } & $\begin{array}{l}\text { Provides speed, flexibility, extended } \\
\text { reach, and interactivity. }\end{array}$ & & $\begin{array}{l}\text { "Social Media and Open } \\
\text { Innovation: A Study } \\
\text { of Geneva-Based } \\
\text { SMEs" } \\
\text { - A.B. Beckh } \\
\text { M. Beck } \\
\text { P.Y. Badillo }\end{array}$ \\
\hline & & $\begin{array}{l}\text { Management tools and platforms for } \\
\text { interactions. }\end{array}$ & $\begin{array}{l}\text { Issues with quality, adequacy diversity, } \\
\text { and efficacy of the collected data. }\end{array}$ & $\begin{array}{l}\text { "Social Media and New } \\
\text { Service Development: } \\
\text { An Exploratory Study } \\
\text { Within a Consulting } \\
\text { Firm" } \\
\text { - M. Bénédic }\end{array}$ \\
\hline & \multirow[t]{3}{*}{ Validate } & $\begin{array}{l}\text { Drives internal co-creativity within an } \\
\text { organization. }\end{array}$ & \multirow[t]{3}{*}{ Centralized control and regulations. } & \\
\hline & & $\begin{array}{l}\text { Reduces market research costs by } \\
\text { providing market insights. }\end{array}$ & & \\
\hline & & $\begin{array}{l}\text { Assists in designing communication } \\
\text { campaigns. }\end{array}$ & & \\
\hline
\end{tabular}




\section{Conclusion}

In conclusion, the book contributes to the growing discussion about the management of DTs during the stages of the OI process, both theoretically and managerially. The book compiles the knowledge of different DTs and the OI process, using different contextual settings to understand how companies can manage the interplay between the two. From a theoretical perspective, it provides a pathway of developing integrated multi-disciplinary frameworks for establishing links between OI and information technology studies. Broadly translating the findings of the chapters in this book, integration of DTs in the OI process can be perceived as a new way of managing, observing and coordinating the activities of the OI process. In addition, the book extends existing knowledge regarding the impact of the digital transformation of innovation processes (Agostini et al., 2017; Urbinati et al., 2018). It is expected to encourage optimistic discussions about innovation open mindedness and mindset, as adoption of DTs during the stages of an OI process, despite facing some resistance, is progressing quickly. It widens the opportunity window for organizations to better optimize, administer and systemize interorganizational, intraorganizational and individual opinions, communications, and collaborations. The OI process operates within business networks which largely rely on different technological platforms for various innovation-related activities to create value for the innovating organization and the involved network stakeholders. The findings of the book extend the discussions about network orchestration and operability within an innovation network, where contributions from multiple stakeholders assist in developing potential and viable products and services. From a strategic point of view, by exploiting the findings of this book, insightful opinions of the contributing researchers can be used for designing frameworks that suggest ways of orchestrating digital capabilities around OI processes to enhance OI outcomes for innovating organizations.

Managerially, the book explores the impact of digital tools and techniques that organizations can incorporate into their innovation processes. The need for DTs varies from stage to stage (ideation, 
R\&D, testing, commercialization), and phase to phase (inbound or outbound), due to the precarious nature of the OI process. The findings in the book suggest ways of managing different dimensions of DTs, by mapping their influence across the activities, across an inbound or outbound OI process through different frameworks and contributions. It opens up areas of robust discussions for organizations to identify relevant skills, resources, routines, and competences for implementing DTs in the activities of OI processes, by realizing the growing demand for the same across different sectors of Industry 4.0. This book also accentuates the need to establish a proactive innovation culture within an organization aligned with the growing demand in the technology-based industry. It further suggests strategies for implementing organizational changes relevant to digital transformation of OI, at the process, individual, team and governance levels, which are important for organizations to implement, due to the complex nature of several DTs, such as big data, the IoT, cloud computing, blockchains, AI, and the boundless reach and implementation of social media. Although the contributions of this book provide key insights into the DTs and OI integration approach, it also points to several areas of future research, and the need for more clarity on understanding the different management methods, to deliver better OI outcomes operating within a digitalized environment.

We would like to thank all the contributors of the book, for sharing the views and research in this book, and believing that the area of OI, integration of DTs and their management is a well-justified area of research which needs more attention, as it is capable of contributing to the development of nuanced innovation approaches and practices for organizational innovation management. With respect to the growing body of insights, we would like to add another $\mathrm{O}$ in the OI practice, and that is Outcome. We believe that the OI approach is focused on delivering translational and commercialized outcomes for all the involved stakeholders and designing reactive approaches to respond to the changing consumer needs. The increasing consideration and demand for integrating DTs into OI practices and developing frameworks for implementation of digitalized strategies for 
enhanced management of the OI process are directed toward achieving stable and sustainable innovation outcomes.

We hope that you find the insights provided in this book to be potential, implementable, and achievable approaches for the better management of digitalized OI processes.

\section{References}

Aagaard, A. and Harrison, X. (2019). Digital Business Models, Springer International Publishing, Gewerbestrasse, Cham, Switzerland.

Adams, R. L. (2017). 10 powerful examples of artificial intelligence in use today. Forbes Technology. Retrieved from http://www.forbes.com/sites/robertadams/ 2017/01/10/10-powerful-examples-of-artificial-intelligence-in-usetoday.

Agafonovas, A. and Alonderiene, R. (2013). Value creation in innovations crowdsourcing: Example of creative agencies. Organizations and Markets in Emerging Economies, 2(1), 7.

Agostini, L., Gastaldi, L., Savino, T. and Appio, F. P. (2017). The digitalization of the innovation process: Challenges and opportunities from a managerial perspective. Retrieved from https://www.emeraldgrouppublishing.com/authors/ writing/calls.htm?id=7345.

Bott, M. and Young, G. (2012). The role of crowdsourcing for better governance in international development. Praxis: The Fletcher Journal of Human Security, 27(1), 47-70.

Brunswicker, S., Bertino, E. and Matei, S. (2015). Big data for open digital innovation - a research roadmap. Big Data Research, 2(2), 53-58.

Bughin, J., Chui, M. and Johnson, B. (2008). The next step in open innovation. The McKinsey Quarterly, 4(6), 1-8.

Cheatham, M. (2015). Privacy in the age of big data. In: 2015 International Conference on Collaboration Technologies and Systems (CTS) (pp. 334-335). IEEE.

Chen, H., Chiang, R. H. and Storey, V. C. (2012). Business intelligence and analytics: From big data to big impact. MIS Quarterly, 36(4), 1165-1188.

Chesbrough, H. W. (2003). Open Innovation: The New Imperative for Creating and Profiting from Technology, Harvard Business School Press, Boston, MA.

Chiaroni, D., Chiesa, V. and Frattini, F. (2011). The open innovation journey: How firms dynamically implement the emerging innovation management paradigm. Technovation, 31(1), 34-43.

Conway, G. and Curry, E. (2012). Managing cloud computing - a life cycle approach. In: CLOSER (pp. 198-207).

Daecher, A., Cotteleer, M. and Holdowsky, J. (2018). The Internet of Things: A Technical Primer, Deloitte Insights. 
De La Rosa, J. L., Torres-Padrosa, V., El-Fakdi, A., Gibovic, D., Hornyák, O., Maicher, L. and Miralles, F. (2017). A survey of blockchain technologies for open innovation. In Proceedings of the 4th Annual World Open Innovation Conference (pp. 14-15). De La Rosa, J. L. and Gibovic, D. (2019). A Survey of Blockchain Technologies for

Open Innovation, In Proceedings of the 4th Annual World Open Innovation Conference (pp. 14-15).

Del Giudice, M. and Della Peruta, M. R. (2016). The impact of IT-based knowledge management systems on internal venturing and innovation: A structural equation modeling approach to corporate performance. Journal of Knowledge Management, 20(3), 484-498.

Dillon, T., Wu, C. and Chang, E. (2010). Cloud computing: Issues and challenges. In 2010: 24th IEEE International Conference on Advanced Information Networking and Applications (pp. 27-33). IEEE.

Duvaut, P., Seulliet, E. and Shavit, D. (2018). La Blockchain pour redonner le pouvoir aux individus. Harvard Business Review France, 10, 20.

Fensel, D., Leiter, B. and Stavrakantonakis, I. (2012). Social Media Monitoring, Semantic Technology Institute, Innsbruck, Germany, p. 16.

Fichman, R. G., Dos Santos, B. L. and Zheng, Z. E. (2014). Digital innovation as a fundamental and powerful concept in the information systems curriculum. MIS Quarterly, 38(2), 329-353.

Foley, J. (2008). Private clouds take shape. Information Week (1104).

Gausdal, A., Czachorowski, K. and Solesvik, M. (2018). Applying blockchain technology: Evidence from Norwegian companies. Sustainability, 10(6), 1985.

Grabs, A., Bannour, K. M. and Vogl, E. (2015). Follow Me! Erfolgreiches Social Media Marketing mit Facebook, Twitter und Co. (in German), 3rd Revised Edition, Rheinwerk Verlag. Bonn, Germany.

Grönlund, J., Sjödin, D. R. and Frishammar, J. (2010). Open innovation and the stage-gate process: A revised model for new product development. California Management Review, 52(3), 106-131.

Gupta, V. (2017). A brief history of blockchain. Harvard Business Review, 28.

Haier. (2018). Haier IoT ecosystem brands: COSMOPlat Mass Customization Platform, retrieved from http://www.haier.net/en/about_haier/news/201807/ t20180725_412004.shtml.

Iqbal, R., Doctor, F., More, B., Mahmud, S. and Yousuf, U. (2018). Big data analytics: Computational intelligence techniques and application areas. Technological Forecasting and Social Change, (In-press). https://doi.org/10.1016/j.techfore. 2018.03.024.

Isse, J. (2010). Cloud Computing and the Innovation Process of Technology Consulting Services: The Case of Accenture (Doctoral dissertation, Master Thesis, Blekinge Institute of Technology).

Kasper, H. and Kett, H. (2011). Social Media Monitoring-tools. Leitfaden OnlineMarketing. Das Wissen der Branche (pp. 662-669). Waghäusel, Germany: Marketing-Börse. 
Kim, A. J. and Ko, E. (2012). Do social media marketing activities enhance customer equity? An empirical study of luxury fashion brand. Journal of Business Research, 65(10), 1480-1486.

Kim, G. H., Trimi, S. and Chung, J. H. (2014). Big-data applications in the government sector. Communications of the ACM, 57(3), 78-85.

Lafley, A. G. and Charan, R. (2014). P \& G's Innovation Culture. Strategy+ Business. Lazazzara, A., Nacamulli, R. C., Rossignoli, C. and Za, S. (2019). Organizing for Digital Innovation, (pp. 1-7). Springer, Cham.

Leminen, S., Rajahonka, M., Westerlund, M. and Siuruainen, R. (2015). Ecosystem business models for the Internet of things. Internet of Things Finland, 10-13.

Longwe, D. (2013). Open Innovation: Mobility Paving the Way for Cloud in Africa. IBM, retrieved from https://www.ibm.com/blogs/cloud-computing/2013/ 02/26/open-innovation-mobility-paving-way-for-cloud-africa/.

Loukis, E., Charalabidis, Y. and Androutsopoulou, A. (2017). Promoting open innovation in the public sector through social media monitoring. Government Information Quarterly, 34(1), 99-109.

Lu, H., Li, Y., Chen, M., Kim, H. and Serikawa, S. (2018). Brain intelligence: Go beyond artificial intelligence. Mobile Networks and Applications, 23(2), $368-375$.

Madakam, S., Ramaswamy, R. and Tripathi, S. (2015). Internet of Things (IoT): A literature review. Journal of Computer and Communications, 3(5), 164.

Manyika, J., Chui, M., Brown, B., Bughin, J., Dobbs, R., Roxburgh, C. and Byers, A. H. (2011). Big Data: The Next Frontier for Innovation, Competition. Washington, DC: McKinsey Global Institute.

Manyika, J., Chui, M., Bisson, P., Woetzel, J., Dobbs, R., Bughin, J. and Aharon, D. (2015). Unlocking the Potential of the Internet of Things. McKinsey Global Institute.

Mention, A. L., Barlatier, P. J. and Josserand, E. (2019). Using social media to leverage and develop dynamic capabilities for innovation. Technological Forecasting and Social Change, 144, 242-250.

Michael, K. and Miller, K. W. (2013). Big data: New opportunities and new challenges [guest editors' introduction]. Computer, 46(6), 22-24.

Misra, S. C. and Mondal, A. (2010). Identification of a company's suitability for the adoption of cloud computing and modelling its corresponding return on investment. Mathematical and Computer Modelling, 53, 504-521.

Morabito, V. (2016). The Future of Digital Business Innovation. Springer International Publishing, Switzerland.

Mount, M. and Martinez, M. G. (2014). Social media: A tool for open innovation. California Management Review, 56(4), 124-143.

Nadeem, A. and Javed, M. Y. (2005). A performance comparison of data encryption algorithms. In 2005 International Conference on Information and Communication Technologies (pp. 84-89). IEEE.

Nakamoto, S. (2008). Bitcoin: A peer-to-peer electronic cash system. Retrieved from http://bitcoin.org/bitcoin.pdf. 
Nambisan, S., Lyytinen, K., Majchrzak, A. and Song, M. (2017). Digital innovation management: Reinventing innovation management research in a digital world. MIS Quarterly, 41(1), 223-238.

Narsalay, R., Brunswicker, S., Bagherzadeh, M. and Kim, J.-W. (2017). Open Innovation at Samsung. Accenture.

Neves, F. T., Marta, F. C., Correia, A. M. R. and Neto, M. D. C. (2011). The Adoption of Cloud Computing by SMEs: Identifying and Coping with External Factors. In CAPSI $2011-11^{a}$ Conferência da Associação Portuguesa de Sistemas de Informação (pp. 1-11). ISEG/IUL-ISCTE.

Nisen, M. (2012). 15 of the Hottest Crowdfunding Sites Out There. Business Insider, http://www.businessinsider.com/trendwatching-presumers-2012-10?op=1.

Nylén, D. and Holmström, J. (2015). Digital innovation strategy: A framework for diagnosing and improving digital product and service innovation. Business Horizons, 58(1), 57-67.

Parida, V., Sjödin, D. and Reim, W. (2019). Reviewing literature on digitalization, business model innovation, and sustainable industry: Past achievements and future promises, 11 (391).

Parveen, F., Jaafar, N. I. and Ainin, S. (2015). Social media usage and organizational performance: Reflections of Malaysian social media managers. Telematics and Informatics, 32(1), 67-78.

Porter, M. E. and Heppelmann, J. E. (2015). How smart, connected products are transforming companies. Harvard Business Review, 93(10), 96-114.

Prashantham, S. (2013). Born global in Bangalore: Emergent pathways for international new ventures via multinational enterprise networks. AIB Insights, 13(4), $13-16$.

Purdy, M. and Daugherty, P. (2017). How AI Boosts Industry Profits and Innovation. Accenture. Retrieved from https://www.accenture.com/fr-fr/_acnme dia/36dc7f76eab444cab6a7f44017cc3997.pdf

Rayna, T. and Striukova, L. (2016). From rapid prototyping to home fabrication: How 3D printing is changing business model innovation. Technological Forecasting and Social Change, 102, 214-224.

Rekece, R., Zimmermann, H. D. and Meili, C. (2012). Studienergebnisse Zum Innovationsmanagement Unter Führungskräften (Open Innovation Monitor 2012).

Reyna, A., Martín, C., Chen, J., Soler, E. and Díaz, M. (2018). On blockchain and its integration with IoT. Challenges and opportunities. Future Generation Computer Systems, 88, 173-190.

Ross, P. K. and Blumenstein, M. (2015). Cloud computing as a facilitator of SME entrepreneurship. Technology Analysis \& Strategic Management, 27(1), 87-101.

Rosyihan, H. M. and Samira, B. A. (2017). Open innovation as a building block for small medium enterprise high-tech in "Internet of Things" era: Case of Indonesia. RJOAS, 11(71), 161-167.

Samani, A., Ghenniwa, H. H. and Wahaishi, A. (2015). Privacy in Internet of Things: A model and protection framework. Procedia - Computer Science, 52, 606-613. 
Santoro, G., Vrontis, D., Thrassou, A. and Dezi, L. (2018). The Internet of Things: Building a knowledge management system for open innovation and knowledge management capacity. Technological Forecasting and Social Change, 136, 347-354.

Sen, D., Ozturk, M. and Vayvay, O. (2016). An overview of big data for growth in SMEs. Procedia - Social and Behavioural Sciences, 235, 159-167.

Sigala, M. and Chalkiti, K. (2015). Knowledge management, social media and employee creativity. International Journal of Hospitality Management, 45, 44-58.

Sjödin, D. R., Parida, V., Leksell, M. and Petrovic, A. (2018). Smart factory implementation and process innovation: A preliminary maturity model for leveraging digitalization in manufacturing moving to smart factories presents specific challenges that can be addressed through a structured approach focused on people, processes, and technologies. Research-Technology Management, 61(5), 22-31.

Solima, L., Della Peruta, M. R. and Del Giudice, M. (2016). Object-generated content and knowledge sharing: The forthcoming impact of the internet of things. Journal of the Knowledge Economy, 7(3), 738-752.

Urbinati, A., Chiaroni, D., Chiesa, V. and Frattini, F. (2018). The role of digital technologies in open innovation processes: An exploratory multiple case study analysis. $R \& D$ Management, $1-1$.

Yamada, N., Tsukuda, M., Nemoto, J., Naganuma, K., Nishjima, N. and Sato, T. (2017). Work on the potential and challenges of blockchain technology. Hitachi Review, 66(1), 31-35.

Yang, C., Huang, Q., Li, Z., Liu, K. and Hu, F. (2017). Big data and cloud computing: Innovation opportunities and challenges. International Journal of Digital Earth, 10(1), 13-53.

Yoo, Y., Boland, Jr., R. J., Lyytinen, K. and Majchrzak, A. (2012). Organizing for innovation in the digitized world. Organization Science, 23(5), 1398-1408.

Zhang, B. and Vos, M. (2014). Social media monitoring aims, methods, and challenges for international companies. Corporate Communications: An International Journal, 19(4), 371-383. 